\title{
The ethics of biosimilars
}

\section{Christian K Schneider, MD}

Comment on the Letters to the Editor by Dr Carlo Petrini: A bioethicist's view of the use of biosimilars, published in GaBI Journal, 2012, issue 3-4.

I n GaBI Journal, 2012, issue 3-4, Dr Carlo Petrini [1] from the Italian National Institute of Health raises an important question-what are the ethical aspects of biosimilars? The participation of a bioethicist in the multidisciplinary debate around biosimilars is most welcome. In fact, ethical issues have been raised on the use of granulocyte colony-stimulating factor (G-CSF, filgrastim) in healthy volunteers by the European Group for Blood and Marrow Transplantation (EBMT) [2] later echoed by the World Marrow Donor Association (WMDA) [3]. The hypothesis is that healthy donors do not have any benefit from donating bone marrow and should therefore receive biosimilar filgrastim only when it has been tested in a clinical study in this particular setting (to confirm its safety), apparently since this indication was obtained by extrapolation of clinical data rather than by a dedicated clinical study, and 'unexpected toxicity' could occur [2]. This recommendation implies a notion that one can experience in numerous debates that there is a certain implicit assumption that biosimilars are less safe, or less 'well tested'. Apparently, this is a good example on how important a thorough understanding of the biosimilar concept is when it comes to ethical considerations. Biosimilars in the EU have to undergo a strictly regulated comparability exercise against the reference medicinal product on the physicochemical, analytical, functional, non-clinical and clinical level [4]. Only if a biosimilar is a close copy of the reference medicine will it be approved as a biosimilar. The mainstay is an extensive comparative characterisation of the biosimilar in all functional aspects of the respective molecule [4]. Clinical data are generated not to re-confirm benefit, but to establish that any small differences that may exist, e.g. due to lack of sensitivity of current methods; do not have any relevant impact on efficacy and safety. This is performed in a sensitive clinical 'model' indication that covers these functional aspects. Extrapolation to other indications is then a logical scientific consequence and a sound scientific principle; every indication granted for authorised biosimilars has been 'actively' granted based on data or justification. The approval history in the EU clearly shows that not every biosimilar was approved, only those that met the stringent criteria were authorised; and such data were made publicly available also in literature [5, 6]. The safety database for a biosimilar is still considerable and can comprise several hundreds of patients [7, 8]. The question is also what 'unexpected toxicity' one would expect, since biologicals mostly have target-mediated toxicity (known from the reference product), and unspecific toxicity would very likely be picked up already in non-clinical and clinical studies before approval. Impurities, which may be able to elicit such unexpected toxicity are tightly controlled as for any other biological, otherwise a biosimilar would not be authorised in the EU, and thus quality concerns are not substantiated. One could say that at the time of approval a biosimilar submits both its own safety data plus the safety data accumulated so far with the reference medicinal product. It is unclear what other unexpected toxicity one could expect.

Dr Petrini takes this (controversially discussed) recommendation by the EBMT up and indicates how multifaceted ethical issues are. One could not agree more - in fact, EBMT recommendation not to use biosimilar filgrastim in this indication has been taken up by national medical societies [9, 10] and there is evidence that biosimilar filgrastims are not, or not widely, used in this indication, and this proves Dr Petrini right - raising ethical questions in the biosimilar debates are multifaceted and, one could add, create further ethical issues. In the 2012, European Generic medicines Association's conference on biosimilars in London, UK [11], a discussant in one of the panel discussions indicated that medical doctors are in an ethical dilemma due to this recommendation. He said that there is evidence from medical practice with filgrastim biosimilars that they work 'the same' as the reference medicines and that money could be saved when using them, but due to the EBMT/WMDA recommendation, physicians cannot use biosimilars in this indication: Would an adverse event occur (and an adverse event would over time inevitably occur - there is no medical intervention without possible side effects!) then the particular doctor would be liable, since he did not follow the EBMT/WMDA recommendation, notwithstanding the fact that the particular adverse event would likely also have occurred with an 'originator' filgrastim. This raises another ethical dilemma: Scientifically not well founded concerns result in lack of trust and lack of uptake of medicines that have the potential to result in significant cost savings in the healthcare systems [12]. These financial resources could be used to either provide an effective treatment to more patients as it was possible before, or they could also be used for innovative new additional or alternative treatments that are often inherently expensive.

Interestingly, even we as regulators could see this recommendation not to accept extrapolation of safety data as an ethical dilemma for our approval procedures. Biological medicinal products like filgrastim often undergo changes in their manufacturing process after approval, and regulatory authorities require a 'comparability exercise' to prove that the change in the manufacturing process did not have any adverse impact on safety and efficacy [13]. In many cases analytical and functional data from in vitro assays are sufficient to claim this, and this helps maintain the manufacturing process of any licensed biological in line with state-of-the-art manufacturing principles, but certainly one could always start asking questions like: Are we really sure that there are not minute differences between pre- and post-change product that could show unexpected toxicity? How should we then handle a change in the manufacturing process for a licensed filgrastim? Should we demand a safety study also for healthy volunteers, or at least clinical data in any case? This answer has been, and should remain: 'no' - this would not necessarily be required from a scientific perspective. One could say that changes in the manufacturing process are not that critical since knowledge with the previous version exists. However, this would be dependent on the type and extent of change. But one could expand this ethical question and take 
it to a more general level, since this aspect may be the real underlying concern: How to justify authorisation and use of a biosimilar when there is an original product with a huge safety database and experience from practical clinical use? Obviously one can take the question to a more general level: How to justify authorisation of treatment option B with a limited database if there is treatment option A with an already extensive database due to its earlier approval and longer availability on the market? In practical terms, one could make deliberations on the following example from the treatment of rheumatoid arthritis with tumour necrosis factor alpha (TNF-alpha) inhibitors: For example, Remicade (infliximab) was licensed in 1999 for Crohn's disease on a 'limited' database 'under exceptional circumstances' [14], and in 2000 for rheumatoid arthritis [15] (NB: example chosen due to availability of publicly available data on patient exposure). Already in 2004, the safety database was considerable: Cumulatively, more than half a million patients had been exposed to infliximab for a total of over a million person-years elapsed since first exposure [16]. Other TNF inhibitors were filed for marketing authorisation later, for example, Simponi (golimumab) or Cimzia (certolizumab pegol) in 2008 [17, 18], that is four years later. While their dossiers contained sufficient number of patients to come to an individual benefit-risk assessment, one could also have asked the aforementioned ethical question in this scenario (if it is valid to ask it for a biosimilar which is highly similar, then one should all the more so ask it for a new active substance where no reference is made and where there are differences between the products): Should we have licensed any other TNF inhibitor, given that others like Remicade, Enbrel and Humira already had a much larger safety database at the time the new ones filed their applications? Should doctors use them, given that there are others already on the market with an 'established' database? Should patients be exposed? The answer is clear: Both Simponi and Cimzia were approved for rheumatoid arthritis, based on their individual positive benefit-risk balance, and both have their place in the rheumatological armamentarium, like the other TNF inhibitors. Surely, this parallel to the biosimilars is on one hand not fair, since new active substances in the same class could have particular advantages like easier administration, reduced immunogenicity or others. On the other hand, if safety, and in particular unexpected safety, is a concern, then it is maybe worth exploring it from a bioethical perspective. Biosimilars make reference to an already authorised reference medicinal product and thus do, in this philosophy, not only file for regulatory approval with data generated with the biosimilar, but, as mentioned before, also with all the data generated with the reference medicinal product.

For me personally, the most important ethical question around biosimilars is: Given the strict rules that are applied for their approval in Europe, how ethical is it to question their safety, and can we afford to question it? Apparently, bioethical questions are multifaceted. The participation of bioethicists in this debate is not only welcome - it is urgently needed.

\section{Disclaimer}

The views expressed in this article are the personal views of the author and may not be understood or quoted as being made on behalf of or reflecting the position of the European Medicines Agency or one of its committees or working parties.

\section{Competing interests: None.}

Provenance and peer review: Commissioned, internally peer reviewed.

\section{References}

1. Petrini C. A bioethicist's view of the use of biosimilars. Generics and Biosimilars Initiative Journal (GaBI Journal). 2012;1(3-4):110-1. doi:10.5639/ gabij.2012.0103-4.034

2. European Group for Blood Marrow Transplantation; Niederwieser D. Biosimilar granulocytecolony stimulating factor (G-CSF) for stem cell mobilization in related and unrelated donors. 2011 [cited 2012 Nov 12]. Available from: www. gitmo.net/Biosimilars_in $\% 20$ mobilization $\% 20$ of $\% 20$ unrelated $\% 20$ and $\% 20$ related $\% 20$ donors.pdf

3. Shaw BE, Confer DL, Hwang WY, Pamphilon DH, Pulsipher MA. Concerns about the use of biosimilar granulocyte colony-stimulating factors for the mobilization of stem cells in normal donors: position of the World Marrow Donor Association. Haematologica. 2011 Jul;96(7):942-7.

4. Schneider CK, Borg JJ, Ehmann F, et al. In support of the EU biosimilar framework. Nat Biotechnol. 2012;30(8):745-8.

5. Brockmeyer C, Seidl A. Binocrit: assessment of quality, safety and efficacy of biopharmaceuticals. Eur J Hosp Pharm Prac. 2009;15(2):34-40.

6. Waller CF. Critical appraisal of biosimilar filgrastim (Nivestim $^{\mathrm{TM}}$ ) for febrile and chemotherapyinduced neutropenia. Biosimilars. 2012;2:1-11.

7. European Medicines Agency [homepage on the Internet]. Retacrit: EPAR - Scientific discussion. 2007 [cited 2012 Nov 12]. Available from: http://
www.ema.europa.eu/docs/en_GB/document_ library/EPAR_-_Scientific_Discussion/human/ 000872/WC500054374.pdf

8. European Medicines Agency [homepage on the Internet]. Abseamed: EPAR - Scientific discussion. 2007 [cited 2012 Nov 12]. Available from: http://www.ema. europa.eu/docs/en_GB/document_library/EPAR_-_Scientific_Discussion/human/000727/WC500020666.pdf

9. Barosi G, Bosi A, Abbracchio MP, et al. Key concepts and critical issues on epoetin and filgrastim biosimilars. A position paper from the Italian Society of Hematology, Italian Society of Experimental Hematology, and Italian Group for Bone Marrow Transplantation. Haematologica. 2011;96(7):937-42.

10. Gastl G, Geissler D, Geissler K, et al. ASHO position on biosimilars. MEMO. 2009;2(4):232-3.

11. European Generic medicines Association [homepage on the Internet]. Biosimilar Medicines: 10th EGA International Symposium on Biosimilar Medicines, London; 19-20 April 2012. Final programme. Available from: http://www.gpaconferences.com/files/ BIOS12_Programme.pdf

12. Cornes P. The economic pressures for biosimilar drug use in cancer medicine. Target Oncol. 2012; 7 Suppl 1:S57-67.

13. Chirino AJ, Mire-Sluis A. Characterizing biological products and assessing comparability following manufacturing changes. Nat Biotechnol. 2004; 22(11):1383-91.

14. European Medicines Agency [homepage on the Internet]. Remicade: EPAR-Scientific Discussion. 2005 [cited 2012 Nov 12]. Available from: http://www.ema. europa.eu/docs/en_GB/document_library/EPAR_Scientific_Discussion/human/000240/WC500050885.pdf

15. European Medicines Agency [homepage on the Internet]. Remicade: EPAR - Steps taken after granting the marketing authorisation. 2005 [cited 2012 Nov 10]. Available from: http://www.ema.europa. eu/docs/en_GB/document_library/EPAR_-_Steps_ taken_after_authorisation_when_a_cutoff_date_ has_been_used/human/000240/WC500050887.pdf

16. European Medicines Agency [homepage on the Internet]. Remicade EMEA/H/C/240/II/69: EPAR Scientific Discussion. 2006 Jul 27 [cited 2012 Nov 12]. http://www.ema.europa.eu/docs/en_GB/document_library/EPAR_-_Scientific_Discussion_-Variation/human/000240/WC500051560.pdf

17. European Medicines Agency [homepage on the Internet]. Simponi EMEA/H/C/000992: EPAR - Public assessment report for Simponi. 2009 [cited 2012 Nov 12]. Available from: http://www.ema.europa. eu/docs/en_GB/document_library/EPAR__Public_ assessment_report/human/000992/WC500052372.pdf

18. European Medicines Agency [homepage on the Internet]. Cimzia EMEA/H/C/001037: EPAR - Public assessment report for Cimzia. 2009 [cited 2012 Nov 12]. Available from: http://www.ema.europa. eu/docs/en_GB/document_library/EPAR_-_Public_ assessment_report/human/001037/WC500069735.pdf DOI: 10.5639/gabij.2013.0201.001

Copyright (C) 2013 Pro Pharma Communications International 